\title{
COMPARSION BETWEEN RENOPROTECTIVE EFFECTS OF CARVEDILOL AND LISINOPRIL IN L-NAME-TREATED RATS
}

\author{
Amany N. Ibrahim ${ }^{1}$, Ayman Mohammed Mousa ${ }^{2}$ \\ ${ }^{1}$ Department of pharmacology, ${ }^{2}$ Department of histology, Faculty of Medicine, Benha \\ University, Egypt.
}

\begin{abstract}
Aim The present study compared the renoprotective effects of curative and prophylactic doses of carvedilol and lisinopril in L-NAME treated rats.

Material and methods Rats were divided into seven groups: the first and second (normal control and hypertensive control) groups received distilled water and L-NAME (L-nitro argentine methyl ester, $50 \mathrm{mg} / \mathrm{kg}$ per day), respectively, for eight weeks. The third and fourth groups received L-NAME $(50 \mathrm{mg} / \mathrm{kg}$ per day) in combination with a prophylactic dose of carvedilol (15mg/kg per day) or lisinopril $(20 \mathrm{mg} / \mathrm{kg}$ per day), respectively, for eight weeks. The fifth, sixth and seventh groups received L-NAME $(50 \mathrm{mg} / \mathrm{kg}$ per day) for eight weeks, followed by curative doses of carvedilol $(30 \mathrm{mg} / \mathrm{kg}$ per day), lisinopril (40mg/kg per day) or carvedilol $(15 \mathrm{mg} / \mathrm{kg}$ per day) in combination with lisinopril $(20 \mathrm{mg} / \mathrm{kg}$ per day), respectively, for five weeks. The drugs were administered by gastric gavage.
\end{abstract}

Results During prophylactic therapy, carvedilol and lisinopril decreased L-NAME induced rise in systolic blood pressure (SBP) and serum creatinine levels. Furthermore, both drugs improved microalbuminuria and renal histopathological changes and increased serum nitric oxide (sNO). During curative therapy, carvedilol improved microalbuminuria and renal histopathological changes. lisinopril or the combination of carvedilol and lisinopril improved all L-NAME induced changes. The combination improved renal histopathological changes more significantly than each individual drug.

Conclusion carvedilol and lisinopril have prophylactic and curative renoprotective effects in L-NAME treated rats. Carvedilol has similar effectiveness as the converting enzyme inhibitor, lisinopril, in reducing the hypertension, proteinuria and glomerulosclerosis associated with L-NAME induced chronic hypertensive renal failure in rats making chronic renal disease as a therapeutic target for this drug. Moreover, a combination of both drugs at half the therapeutic doses significantly ameliorated hypertension-induced renal damage and improved renal functions, indicating the role of this low-dose combination as an effective therapeutic option if a multi-anti-hypertensive regimen is desirable.

Key words: carvedilol, lisinopril, L-NAME, nitric oxide

\section{INTRODUCTION:}

The renin-angiotensin system plays a major role in blood pressure regulation and hypertension. Angiotensin converting enzyme (ACE) inhibitors reduce production of angiotensin II (Ang II) and have proven to be very useful antihypertensive agents. They have pleiotropic effects and studies have reported that both captopril and ramipril are cardioprotective in an animal model of the metabolic syndrome and cardiovascular disease (Russell, et al., 1998). ARBs have been viewed as useful adjuncts to the treatment of cardiovascular disease because of their antihypertensive effects. However, there are recent indications that the effects of ARBs may be broader and include direct beneficial effects on diabetic vasculopathy (Karalliedde, et al., 2008; Negro, 2008). 
The blood pressure-independent role of the renin-angiotensin system (RAS) in progressive deterioration of renal function has been firmly established in animal experiments (Rennke, Klein, 1989; Remuzzi, Bertani, 1998). In addition, in renal patients, angiotensinconverting enzyme (ACE) inhibitors as well as angiotensin receptor blockers have been shown to ameliorate progression (Lewis, et al., 2001; Brenner, et al., 2001). It is possible that better control of glomerular hypertension and/or inhbition of the proliferative effects of angiotensin II by ACE inhibitors may be important factors in the possible advantage of this class of drugs over other antihypertensive agents.

Rump et al. (1999) documented activation of the sympathetic nervous system (SNS) in models of renal damage. In addition, blockade of sympathetic activity either by a central sympathetic inhibitor (Amann, et al., 2000) or a $\beta$-blocker (Amann, et al., 2001) attenuated progression independently of blood pressure in the remnant kidney model. One of the main effects of the SNS in the kidney is activation of the juxtaglomerular apparatus (Ye, et al., 2002). Carvedilol is known to be an adrenoreceptor blocker and free radical scavenger, used in hypertension and cardiac failure. However, its therapeutic actions cannot be fully explained by these mechanisms.

In this study, we tested the hypothesis that carvedilol action is associated with the synthesis/release of nitric oxide (NO). In addition, we evaluated the hypothesis that low prophylactic doses, single curative doses or combined prophylactic doses of lisinopril and carvedilol might be protective against renal damage in hypertension. To prove this, we used L-nitro-arginine methyl ester (L-NAME)-treated rats because this model of hypertension is characterized by the severity of renal lesions (Xu, et al., 1995).

\section{MATERIAL AND METHODS}

\section{1-Animals:}

The present study was conducted in adult male albino rats, weighting (120-150gm). They were brought from Experimental Animal Breeding Farm, Helwan - Cairo .All animals were housed in controlled laboratory condition at $20-25 \mathrm{C}$ in a $12 \mathrm{~h}$ light/dark cycle and had free access to standard laboratory chow (El-Nasr Company, Abou-Zaabal, Cairo, Egypt) and water. They were acclimatized for one week and were caged (10/cage) in fully ventilated room (at room temperature) in Pharmacology Department, Benha Faculty of Medicine from September 2011-February 2012. All experimental protocols were approved by the ethics committee of Benha University.

\section{2-Experimental model: induction of hypertension in rats:}

L-NAME $(50 \mathrm{mg} / \mathrm{kg}$ day) was administered to rats by gastric gavage for eight weeks. By the inhibition of nitric oxide synthase (NOS), chronic L-NAME treatment increases systolic load because nitric oxide and its donors increase cyclic GMP, causing vasorelaxation; a withdrawal of constitutive NO induces vasoconstriction; causing sever hypertension (Bartunek, et al., 2000) Systolic blood pressure (SBP) was measured by the direct tail-cuff method (Harverd apparatus, 52-0338) and registered by a chart recorder (Pfeffer, et l., 1971) SBP was recorded at the start of the experiment, weekly and after eight weeks. Rats were considered to be hypertensive if SBP was $>120 \mathrm{mmHg}$. In the curative therapy protocol, SBP was measured weekly and at the end of the fifth week of treatment. 


\section{3-Treatment protocols:}

The rats were divided into seven groups $(n=6)$ : the first and second (normal control and hypertensive control) groups received distilled water and L-NAME (50 $\mathrm{mg} / \mathrm{kg}$ day), respectively, for eight weeks. The third and fourth groups received L-NAME $(50 \mathrm{mg} / \mathrm{kg} /$ day) plus prophylactic doses of lisinopril $(5 \mathrm{mg} / \mathrm{kg} /$ day) or carvedilol $(15 \mathrm{mg} / \mathrm{kg}$ day), respectively, for eight weeks. The fifth, sixth and seventh groups received L-NAME $(50 \mathrm{mg} / \mathrm{kg} /$ day) for eight weeks, followed by curative doses of lisinopril (10mg/kg per day), carvedilol (30 mg/kg /day) or lisinopril plus carvedilol $(5+15 \mathrm{mg} / \mathrm{kg} /$ day), respectively, for five weeks. SBP was recorded at the start of the experiment, weekly and after eight weeks then during treatment with drugs it was measured weekly and at the end of the fifth week. Biochemical data and histopathological changes were performed at the end of 8 weeks in the control and prophylactic groups and at the end of 5 weeks of treatment in the curative groups.

The drugs were administered by gastric gavage. The dosages of the drugs used were based on the literature reported: Zoja et al. (2003) used lisinopril (40mg/kg / day) and reported that it prevented the development of renal damage in an L-NAME rat model. Kozlovski et al. (2006) used carvedilol $(3-30 \mathrm{mg} / \mathrm{kg} /$ day) and reported that it prevented the development of cardiac damage in L-NAME hypertension.

\section{Estimation of renal excretion of albumin:}

All rats were housed individually in metabolic cages for 24 hours with free access to water and a normal chow. Albumin concentrations were measured in 24-hour urine $(\mathrm{mg} / 24$ hours) samples using a Minineph microalbumin kit (The Binding Site, Birmingham, UK) (Showell, et al., 2002).

\section{Measurement of serum creatinine and nitric oxide:}

Blood samples were collected from the retro-orbital plexus (Timm, 1979).

\section{Creatinine:}

The kit used for measuring creatinine levels (Randox Laboratories, Crumlin, Country Antrim, UK) is based on the Jaffe reaction. In an alkaline solution, creatinine combines with picric acid to form an orange-red complex (the creatinine-picric acid complex). The increase in absorbance using a spectrophotometer at $510 \mathrm{~nm}$ is proportional to creatinine concentration (in $\mu \mathrm{mol} / \mathrm{L}$ ) (Jaffe, 1886).

\section{Nitric oxide:}

The concentration of serum nitrate (a stable end product of $\mathrm{NO}$, in $\mu \mathrm{mol} / \mathrm{l}$ ) was measured by a one-step enzymatic assay using nitrate reductase (Roche diagnostic group, Basel, Switzerland). The concomitant reduction of nitrate o nitrite by NADPH was reflected by the oxidation of the coenzyme and the decrease in absorbance using a spectrophotometer at $340 \mathrm{~nm}$ (Bories, Bories, 1995).

\section{Histopathological kidney examination:}

The rats in all groups were sacrificed, and their kidneys were harvested; each kidney was divided into two halves. The specimens were preserved in $10 \%$ formalin, dehydrated in ascending grades of ethyl alcohol (50\%, 70\%, 90\% and 100\%) and cleared; the two halves were embedded in soft and hard paraffin, respectively. Paraffin blocks were generated, and sections $(3-\mu \mathrm{m}$ thick) were cut on a microtome and subjected to haematoxylin and eosin staining. For statistical analysis, the number of affected renal tubules per 100 tubules was counted in each section, as evidence by nuclear changes (e.g. pyknosis, karyorrhexis and 
karyolysis), cytoplasmic changes as (vacuolation) or sloughing of epithelial debris into the lumen of the tubules (Ono, et al., 1995).

\section{Statistical analysis:}

Data are presented as mean \pm SEM. Multiple comparisons were performed using oneway analysis of variance (ANOVA) followed by Turkeys' test as a post-hoc test. The 0.05 level of probability was used as the criterion for significance.

\section{RESULTS:}

\section{1-L-NAME -induced changes in rats:}

L-NAME administration $(50 \mathrm{mg} / \mathrm{kg} /$ day for eight weeks) significantly reduced serum NO levels and increased SBP, renal albumin excretion and serum creatinine levels. L-NAME produced significant widening of Bowman's space, congestion of glomerular capillaries and areas of haemorrhage between the renal tubules.

\section{2- Effects of carvedilol and lisinopril administration on L-Name-Induced changes:}

Prophylactic doses of carvedilol and lisinopril significantly reduced the effect of LNAME on SBP, but no significant difference was noted on comparison with the normal control and between the two treatment groups (Figure 1A). In addition, the curative dose of lisinopril, carvedilol and the combination produced a significant reduction in SBP with no such difference between the latter two groups (table 1,2)

Table 1: Effects of L-NAME administration $(50 \mathrm{mg} / \mathrm{kg} /$ day for eight weeks) on systolic blood pressure $(\mathrm{mmHg})$ in rats.

\begin{tabular}{|l|l|l|l|l|l|l|l|l|l|}
\hline Group & Start & $\mathbf{1}^{\text {st }}$ week & $\mathbf{2}^{\text {nd }}$ week & $\mathbf{3}^{\text {rd }}$ week & $\mathbf{4}^{\text {th }}$ week & $\mathbf{5}^{\text {th }}$ week & $\mathbf{6}^{\text {th }}$ week & $\mathbf{7}^{\text {th }}$ week & $\mathbf{8}^{\text {th }}$ week \\
\hline NC & $78.5 \pm 4.89$ & $79.17 \pm 2.70$ & $82 \pm 5.62$ & $100.5 \pm 1.95$ & $98 \pm 1.93$ & $99.5 \pm 1.61$ & $100.2 \pm 2.87$ & $105.33 \pm 2.39$ & $102.67 \pm 8.32$ \\
\hline HC & $81.45 \pm 2.39$ & $99.33 \pm 1.15$ & $114.17 \pm 3.01$ & $117.5 \pm 3.82$ & $124.17 \pm 2.5$ & $137.8 \pm 2.5$ & $158.7 \pm 2.26$ & $162.7 \pm 0.7$ & $173.3 \pm 11.4 *$ \\
\hline
\end{tabular}

Table 2: Effects of lisinopril and carvedilol given prophylactically (L-N+L, L-N+C: LNAME $(50 \mathrm{mg} / \mathrm{kg} /$ day $)+(20 \mathrm{mg} / \mathrm{kg} /$ day $)$ lisinopril or carvedilol $(15 \mathrm{mg} / \mathrm{kg} /$ day $)$ for eight weeks) on systolic blood pressure $(\mathrm{mmHg})$ in rats.

\begin{tabular}{|l|l|l|l|l|l|l|l|l|l|}
\hline Group & Start & $\mathbf{1}^{\text {st }}$ week & $\mathbf{2}^{\text {nd }}$ week & $\mathbf{3}^{\text {rd }}$ week & $\mathbf{4}^{\text {th }}$ week & $\mathbf{5}^{\text {th }}$ week & $\mathbf{6}^{\text {th }}$ week & $\mathbf{7}^{\text {th }}$ week & $\mathbf{8}^{\text {th }}$ week \\
\hline $\begin{array}{l}\text { L- } \\
\text { NAME+C }\end{array}$ & $79.17 \pm 2.2 .7$ & $92.3 \pm 2.77$ & $98.5 \pm 1.73$ & $97.83 \pm 2.1$ & $99-67 \pm 0.67$ & $101 \pm 1.71$ & $117.5 \pm 3.82$ & $121.33 \pm 3.2$ & $128.67 \pm 6.21 *$ \\
\hline $\begin{array}{l}\text { L- } \\
\text { NAME+L }\end{array}$ & $82 \pm 5.6$ & $96 \pm 1.48$ & $99.33 \pm 1.15$ & $98.33 \pm 1.76$ & $100.27 \pm 0.87$ & $92.27 \pm 2.76$ & $111.33 \pm 6.13$ & $121.8 \pm 2.7$ & $\begin{array}{l}123.67 \pm 11.21 \\
*\end{array}$ \\
\hline
\end{tabular}

\section{3- Serum NO levels:}

Prophylactic doses of carvedilol and lisinopril significantly mitigated the effect of LNAME on $\mathrm{SNO}$ with no difference between therapies (figure 1; B). Furthermore, a curative dose of lisinopril and carvedilol significantly increase serum NO levels with no difference between therapies.

\section{4- Renal excretion of albumin:}

Prophylactic doses of lisinopril and carvedilol significantly reduced the effects of LNAME on renal albumin excretion, but no significant differences were noted when compared with the normal control and between the two treatment groups (figure 1; c). 
Moreover, curative doses of lisinopril, carvedilol and their combination significantly reduced renal albumin excretion, but no significant differences were noted when compared with normal control or between the three treatment groups.

\section{5- Serum creatinine levels:}

Prophylactic doses of lisinopril and carvedilol significantly inhibited the effects of LNAME on serum creatinine, but no significant difference was noted when compared with the normal control or between the two treatment groups (figure 1; D). In addition, the curative dose of lisinopril and carvedilol significantly reduce serum creatinine levels with no difference between the three treatment groups.

\section{6- Renal histopathological structure:}

Prophylactic doses of lisinopril and carvedilol significantly reduced the effects of LNAME on renal structure. Moreover, curative doses of lisinopril, carvedilol and their combination significantly decreased the percentage of affected renal tubules, this was more pronounced in the combination group. The combination produced a more significant decrease than each individual drug did (figure $1 ; \mathrm{E}$ ) and (figures $2 ; \mathrm{E}, \mathrm{F}$ and $\mathrm{G}$ ).

Table (3): Effects of carvedilol (C, 30mg/kg/ day), lisinopril (L, $40 \mathrm{mg} / \mathrm{kg} /$ day) or carvedilol + lisinopril $(\mathrm{C}+\mathrm{L}: 15+20 \mathrm{mg} / \mathrm{kg} /$ day $)$ given curatively for five weeks on systolic blood pressure $(\mathrm{mmHg})$ in L-NAMEinduced hypertensive rats.

\begin{tabular}{lllllll}
\hline Group & Start & $1^{\text {st }}$ week & $2^{\text {nd }}$ week & $3^{\text {rd }}$ week & $4^{\text {th }}$ week & $5^{\text {th }}$ week \\
C & $181.2 \pm 1.32$ & $178.5 \pm 1.23$ & $174.33 \pm 1.31$ & $167.5 \pm 2.67$ & $164 \pm 0.52$ & $151.33 \pm 8.82$ \\
L & $184 \pm 1.93$ & $176.2 \pm 1.17$ & $160.33 \pm 3.05$ & $135.7 \pm 2.32$ & $125.7 \pm 7.76$ & $118.33 \pm 6.96^{*}$ \\
C+L & $178.5 \pm 1.23$ & $169.7 \pm 3.06$ & $158.7 \pm 2.26$ & $138 \pm 2.75$ & $121.3 \pm 2.17$ & $120 \pm 7.68^{*}$ \\
\hline
\end{tabular}

Significant difference at $\mathrm{p}<0.05$ vs. hypertensive control $(\mathrm{HC})$. 


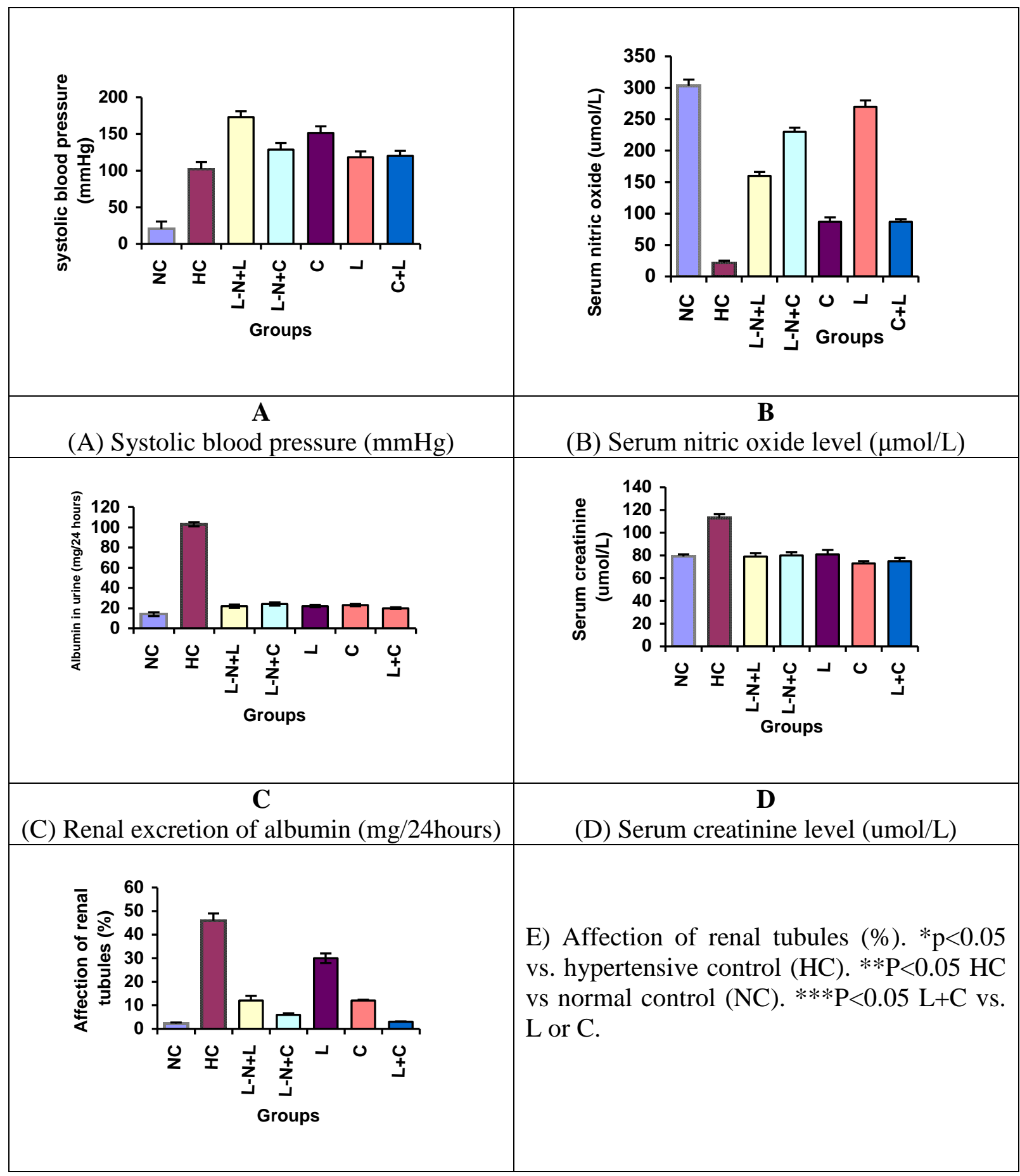

Figure 1. Effects of carvedilol and lisinopril given either prophylactically (L-N+C, L-N+L: L-NAME $(50 \mathrm{mg} / \mathrm{KG}$ per day) + carvedilol $(15 \mathrm{mg} / \mathrm{kg}$ per day) or lisinopril (lisinopril, $20 \mathrm{mg} / \mathrm{kg}$ per day) for eight weeks then carvedilol (C, $15 \mathrm{mg} / \mathrm{kg}$ per day), lisinopril (L, $20 \mathrm{mg} / \mathrm{kg}$ per day) for five weeks in L-NAME -treated rats on: 


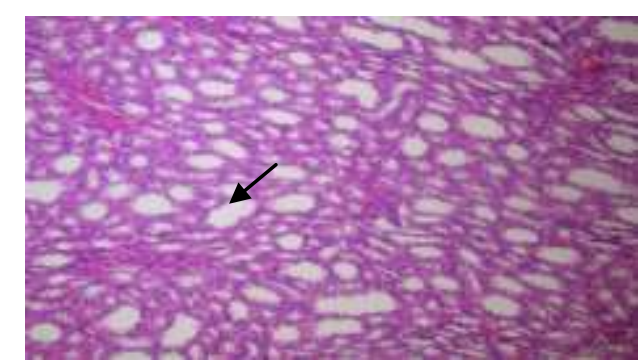

A) Normal control group

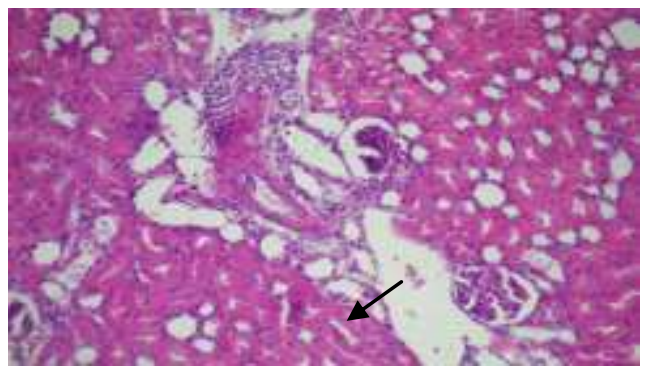

C) Prophylactic carvedilol group (L-NAME+ carved $\mathrm{mg} / \mathrm{kg}$ per day for eight weeks), showing congested glomerular capillary and degenerative changes in the tubules

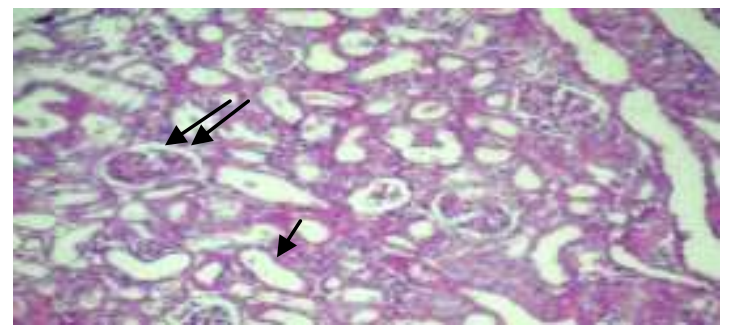

E) Curative carvedilol group (L-NAME $50 \mathrm{mg} / \mathrm{kg}$ per day For 8 weeks the carvedilol $30 \mathrm{mg} / \mathrm{kg}$ per day for 5 weeks), Showing wide tubules and results similar to those of The normal control

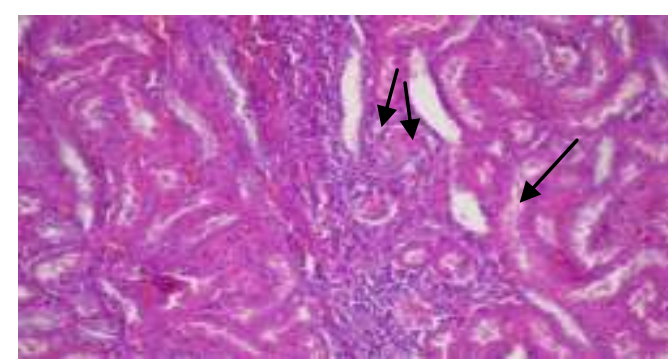

B) Hypertensive control group showing wide Bowman's Space, congested glomerular capillaries (2 arrow) and Degenerative tubules (one head arrow)

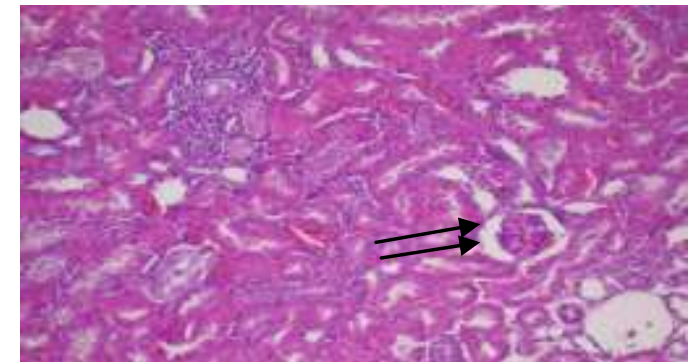

+15 D) prophylactic lisinopril group (L-NAME+ Lisinopril: $50+20 \mathrm{mg} / \mathrm{kg}$ per day for eight weeks), Showing results similar to those of the normal the Control group

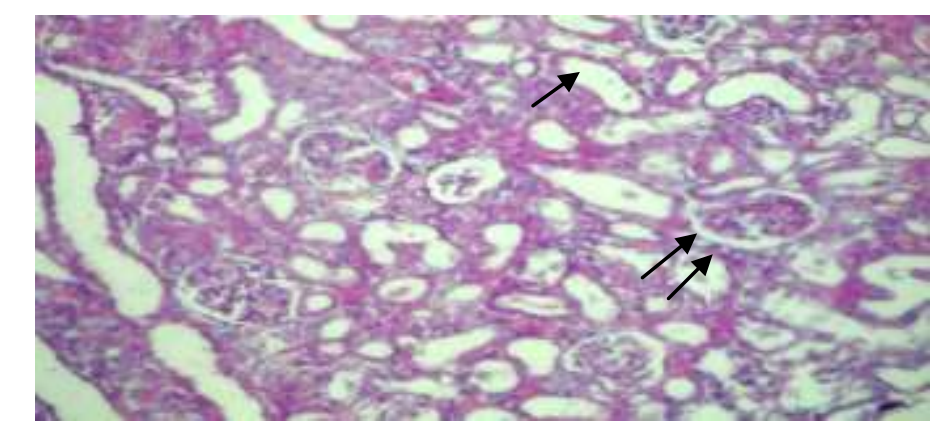

G) Curative carvedilol+lisinopril group (L-NAME 50mg/kg per day for eight weeks then carvedilol+lisinopril: $15+20$ $\mathrm{mg} / \mathrm{kg}$ per day for five weeks), showing results similar to those of the normal control group

\section{DISCUSSION:}

The current study showed that prophylactic therapy with lisinopril significantly reduced the effects of L-NAME on SBP, sNO and serum creatinine levels and improved microalbuminuria and renal histological changes. Moreover, curative therapy with lisinopril yield significant effects in decreasing SBP, increasing serum NO, reduced microalbuminuria, reduced renal structure alternation and reducing serum creatinine levels. These findings are 
congruent with those of Buikema et al. (2000) who noted that ACE inhibitors has a potential advantage in improvement of endothelial dysfunction through increased activity of NO after release from the endothelium into the vessel wall in experimental heart failure rats. ACEIs can potentiate NO release and subsequent functional restoration of the vascular endothelium, perhaps by increasing tissue levels of bradykinin, up-regulatiing eNOS and scavenging basally released oxygen-derived free radicals (Fujiki, et al., 2005). Moreover, Oktem et al. (2011) reported that lisinopril significantly ameliorated proteinuria and improved glomerular, arteriolar and tubulointerstitial lesions in L-NAME hypertensive rats. The blood pressure independent tissue-protective mechanisms of lisinopril might be related to reduction of oxidative stress (Oktem et al., 2011).

In this study, prophylactic therapy with carvedilol significantly reduced the effects of L-NAME on SBP, sNO levels and serum creatinine levels and improved microalbuminuria and renal histopathological alternations. Furthermore, curative therapy with carvedilol significantly decreased and normalized SBP; increased sNO levels and reduced serum creatinine levels, microalbuminuria and renal alternations. The observed increase in sNO level by carvedilol corresponds with the finding of Afonso et al. (2006) who reported that simultaneous treatment of rats with L-NAME and carvedilol preserved sNOS activity without affecting iNOS levels. Moreover, carvedilol can potentiate NO release and subsequent functional restoration of the vascular endothelium, perhaps by up-regulating NOS and scavenging basally released oxygen-derived free radicals (Hayashi, et al., 2010). These findings correspond to those of Di Verniero et al. (2010) who reported that the simultaneous treatment of wistar rats with L-NAME and carvedilol prevented hypertension by lowering enhanced sympathetic tone. In addition, carvedilol increases NO bioavailability and improves impaired endothelial function by decreasing oxidative stress and generating anti-hypertensive and protective effects on renal injury (Yasar, et al., 2012).

In the present study, curative therapy with the combination of carvedilol and lisinopril significantly decreased and normalized SBP, increased sNO levels and reduced serum creatinine levels, microalbuminuria and renal alternations. This combination improved renal structure more significantly than either individual drug did. These findings are supported by those of previous studies, where the administration of carvedilol with ACEI significantly reduced albuminuria in renal transplant recipients (Tylicki, et al., 2006). In addition, the combination of carvedilol and ACEIs was observed to provide a better $\mathrm{NO} / \mathrm{O}^{2-}$ balanced via markeded up-regulation of eNO by the ACEI and significant lowering of O2formation by the carvedilol (Hamar, et al., 2007) Furthermore, pretreatment with carvedilol or lisinopril reduces protein excretion in urine and caused significant reduction of glomerular volume and podocyte hypertrophy, the effects being more profound when both drugs are combined (Hamar, et al., 2007).

Jawa et al. (2008) found that combination therapy of ACEI with carvedilol was more effective than ACEI monotherapy to reduce proteinuria in diabetic hypertensive patients with proteinuric renal diseases. In addition, Bakris et al. (2008) demonstrated that in patients whose blood pressure was not controlled with a lisiopril, the addition of carvedilol over a 6week period significantly lowered systolic BP. Carvedilol, therefore, may be useful add-on therapy in hypertensive patients inadequately controlled on ACE inhibitors alone.

In conclusion, carvedilol and lisinopril have prophylactic and curative renoprotective effects in L-NAME- treated rats. Moreover, a combination of both drugs at half the therapeutic doses significantly ameliorated hypertension-induced renal damage and improves renal functions, indicating the role of this low-dose combination as an effective therapeutic option if a multi-anti-hypertensive regimen is desirable. 


\section{REFERENCES:}

Afonso, RA. Patarrao, RS. Macedo, MP. et al. 2006: Carvedilol action is dependent on endogenous production of nitric oxide. Am J Hypertens.Apr; 19 (4):419-425.

Amann, K. Koch, A. Hofstetter, J. et al. 2001: Glomerulosclerosis and progression: effect of subantihypertensive doses of alpha and beta blockers. Kidney Int 60:1309-1323.

Amann, K. Rump, LC. Simonaviciene, A. et al. 2000: Effects of low dose sympathetic inhibition on glomerulosclerosis and albuminuria in subtotally nephrectomized rats. J Am Soc Nephrol; 11:1469-1478.

Bakris, GL. Iyengar, M. Lukas, MA. et al. 2010: Effect of combining extended-release carvedilol and lisinopril in hypertension: results of the COSMOS study. J Clin Hypertens (Greenwich). Sep; 12(9):678-686.

Bartunek, J. Weinberg, EO. Tajima, M. et al. 2000: Chronic N(G)-nitro-L-arginine methyl ester-induced hypertension : novel molecular adaptation to systolic load in absence of hypertrophy. Circulation. Feb 1; 101(4):423-429.

Bories, PN. Bories, C.1995: Nitrate determination in biological fluids by an enzymatic nestep assay with nitrate reductase. Clin Chem. Jun; 41(6 Pt 1):904-907.

Brenner, BM. Cooper, ME. de Zeeuw, D. et al. 2001: Effects of losartan on renal and cardiovascular outcomes in patients with type 2 diabetes and nephropathy. $\mathrm{N}$ Engl J Med; 345:861-869.

Buikema, H. Monnink, SH. Tio, RA. et al. 2000: Comparison of zofenopril and lisinopril to study the role of the sulfhydryl-group in improvement of endothelial dysfunction with ACE-inhibitors in experimental heart failure. Br J Pharmacol. Aug; 130(8):1999-2007

Di Verniero, CA. Bertera, F. Buontempo, F. 2010: Enantioselective pharmacokineticpharmacodynamic modeling of carvedilol in a N-nitro-l-argenine methyl ester rat model of secondary hypertension. J Pharm Pharmacology. Jul; 62 (7):890-900.

Fujiki, T. Shimokawa, H. Morikawa, K. et al. 2005: Endothelium-derived hydrogen peroxide accounts for the enhancing effect of anangiotensinconverting enzyme inhibitor on endothelium-derived hyperpolarizing factormediated responses in mice. Arterioscler Thromb Vasc Biol. Apr; 25(4):766771.

Hamar, P. Kokeny, G. Liptak, P. et al. 2007: The combination of ACE inhibition plus sympathetic denervation is superior to ACE inhibitor monotherapy in the rat renal ablation model. Nephron Exp Nephrol. ; 105(4):e124-136.

Hayashi, T. De Velasco, MA. Saitou, Y. et al. 2010: Carvedilol protects tubular epithelial cells from ischemia-reperfusion injury by inhibiting oxidative stress. Int $\mathrm{J}$ Urol. Dec; 17(12):989-95.

Jaffe, M. 1886: Uber den Niederschlag welchen Pikrinsature in normalem Harn erzeugt und uber eine neue Reaction des Kreatinins. Zeitschrift Fur Physiologische Chemie 10:391-400. 
Jawa, A. Nachimuthu, S. Pendergrass, M. et al. 2008: Beta-blockers have a beneficial effect upon endothelial function and microalbuminuria in African-American subjects with diabetes and hypertension. J Diabetes Complications. Sep-Oct; 22(5):303-308.

Karalliedde, J. Smith, A. DeAngelis, L. et al. 2008: Valsartan improves arterial stiffness in type 2 diabetes independently of blood pressure lowering. Hypertension. Jun; 51(6):1617-23.

Kozlovski, VI. Lomnicka, M. Chlopicki, S. 2006: Nebivovol and carvedilol induce NOdependent coronary vasodilatation that is unlikely to be mediated by extracellular ATP in the isolated guinea pig heart. Pharmacol Rep. ;58 Suppl: 103-110.

Lewis, EJ. Hunsicker, LG. Clarke, WR. et al. 2001: Renoprotective effect of the angiotensin-receptor antagonist irbesartan in patients with nephropathy due to type 2 diabetes. N Engl J Med; 345:851-860.

Negro, R. 2008: Endothelial effects of antihypertensive treatment: focus on irbesartan. Vasc Health Risk Manag; 4(1):89-101

Oktem, F. Kirbas, A. Armagan, A. et al. 2011: Lisinopril attenuates renal oxidative injury in L-NAME-induced hypertensive rats. Mol Cell Biochem. Jun; 3 52(12):247-53.

Ono, H. Ono, Y. Frohlich, ED. 1995: Nitric oxide synthase inhibition in spontaneously hypertensive rats. Systemic,renal, and glomerular hemodynamics. Hypertension. Aug; 26(2):249-55.

Pfeffer, JM. Pfeffer, MA. Frohlich, ED. 1971: Validity of an indirect tail-cuff method for determining systolic arterial pressure in unanesthetized normotensive and spontaneously hypertensive rats. J Lab Clin Med. Dec; 78(6):957-62.

Remuzzi, G. Bertani, T. 1998: Pathophysiology of progressive nephropathies. N Engl J Med; 339:1448-1456.

Rennke, HG. Klein, PS. 1989: Pathogenesis and significance of nonprimary focal and segmental glomerulosclerosis. Am J Kidney Dis; 13:443-456.

Rump, LC. Oberhauser, V. 1999: Chronic renal failure - taming the sympathetic nervous system! New approach to delaying progression. MMW Fortschr Med;141:39-41

Russell, JC. Graham, SE. Amy, RM. 1998: Inhibition of myocardial lesions in the JCR: LA-corpulent rat by captopril. J Cardiovasc Pharmacol. Jun; 31(6):971-977.

Showell, P., Matters, D.J., Long, J.M., et al. 2002: Evaluation of latex-enhanced nephelometric reagents for measuring free immunoglobulin light-chains on a modified miniephTM. Clinical Chemistry 48:A67.

Timm, KI. 1979: Orbital venous anatomy of the rat. Lab Anim Sci. Oct; 29(5):636-638.

Tylicki, L. Biedunkiewicz, B. Chamienia, A. et al. 2006: Randomized placebo-controlled study on the effects of losartan and carvedilolon albuminuria in renal transplant recipients. Transplantation. Jan 15; 81(1):52-6.

Xu, Y. Arnal, JF. Hinglais, N. et al. 1995: Renal hypertensive angiopathy. Comparison between chronic NO suppression and DOCA-salt intoxication. Am J Hypertens. Feb; 8(2):167-76. 
Yasar, A. Erdemir, F. Parlaktas, BS. et al. 2012: The effect of carvedilol on serum and tissue oxidative stress parameters in partial ureteral obstruction induced rat model. Kaohsiung J Med Sci. Jan; 29(1):19-25.

Ye, S. Zhong, H. Yanamadala, V. et al. 2002: Renal injury caused by intrarenal injection of phenol increases afferent and efferent renal sympathetic nerve activity. Am J Hypertens; 15:717-724.

Zoja, C. Benigni, A. Camozzi, D. et al. 2003: Combining lisinopril and 1-arginine slows disease progression and reduces endothelin-1 in passive Heymann nephritis. Kidney Int. Sep; 64(3):857-863.

\section{دراسة مقارنة تاثيرات وقائية للكلى بين الكارفيديلول واليزانوبريل فى الفئران المعالجة بالدنام}

$$
\begin{aligned}
& \text { ' امانى نصر ابراهيم - ' أيمن محمد موسي } \\
& \text { 'قسم الفارماكولوجى _ـ قسم الهتستولوجي _كلية الطب البشرى ــامعة بنها ـ- مصر }
\end{aligned}
$$

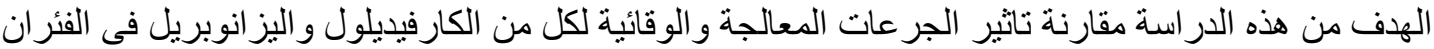

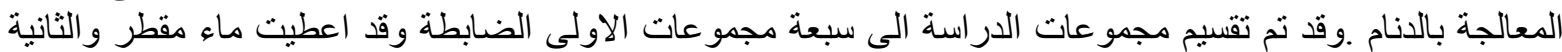

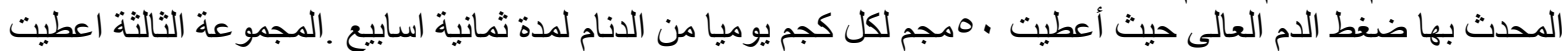

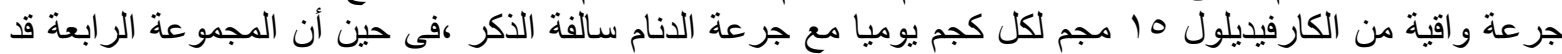

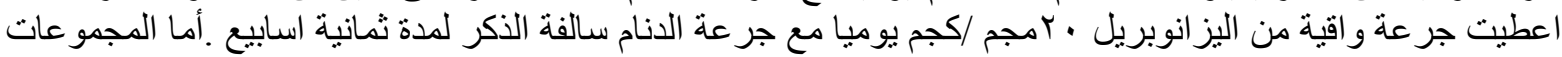

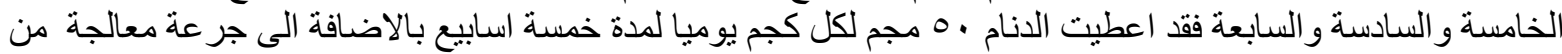

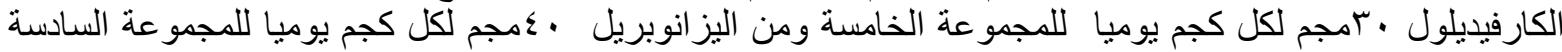

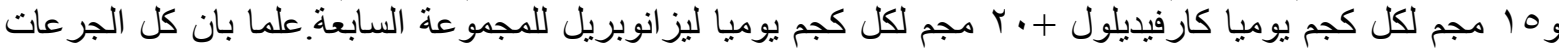
أخذت عن طريق الفه.

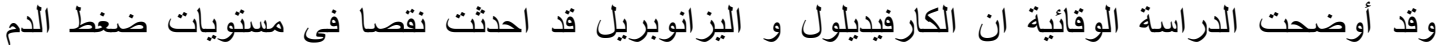

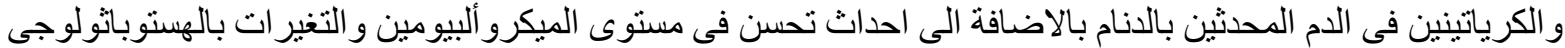

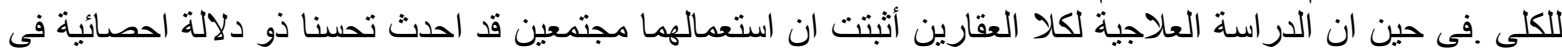
التغير ات الهستو باثولو لوجية عنه فى حال استخدام الى منهما منفردا و الخلاصة أن الكارفيديلول و واليز انوبريل لهما تاثثير و اقى و علاجى للتأثير ات المحدثة بو اسطة الدنام فى الفئران. 